\title{
Callosal Projections Drive Neuronal-Specific Responses in the Mouse Auditory Cortex
}

\author{
(1)Crystal Rock and Alfonso junior Apicella \\ Department of Biology, Neuroscience Institute, University of Texas at San Antonio, San Antonio, Texas 78249
}

In the auditory cortex (AC), interhemispheric communication is involved in sound localization processes underlying spatial hearing. However, the neuronal microcircuits recruited by the callosal projections are unknown. We addressed this fundamental question by taking advantage of optogenetics and examining directly the functional effects of interhemispheric inputs to specific pyramidal neurons in layer 5 of the mouse AC, defined by their output as either corticocortical (CCort) or corticocollicular (CCol). We found that callosal projections suppress the activity of CCort pyramidal neurons, but facilitate firing of CCol pyramidal neurons. This difference is mechanistically explained by callosal activation of fast-spiking parvalbumin-expressing interneurons (FS-PARV), which provide selective inhibition to CCort pyramidal neurons. Our results establish two distinct previously unknown cortical circuits underlying either callosal suppression (callosal projections $\rightarrow$ FS-PARV $\rightarrow$ CCort) or facilitation (callosal projections $\rightarrow$ CCol) of projecting neurons in layer 5 of the $\mathrm{AC}$ and attribute a specific function to a genetically defined type of interneuron in interhemispheric communication.

Key words: auditory cortex; excitation; feedforward; inferior colliculus; inhibition; interhemispheric communication

\section{Introduction}

The ability of the auditory cortex (AC) to perform sound localization processes that underlie spatial hearing involves communication between the two cerebral hemispheres via the corpus callosum. (Poirier et al., 1993; Poirier et al., 1995; Lepore et al., 1997; Bamiou et al., 2007). The axons of callosal projections release the excitatory neurotransmitter glutamate, but, contrary to how it may seem, callosal projections may not serve to simply combine interhemispheric excitatory signals. A number of studies have suggested that the two hemispheres can inhibit each other via callosal projections (for review, see Bloom and Hynd, 2005). Therefore, an important unsolved question is aimed at understanding how callosal projections influence the transfer of information between the two hemispheres: does it occur via excitation or inhibition?

Past and current studies using electrical stimulation, cooling, electrophysiological, and pharmacological approaches are beginning to reveal the functional impact that each AC has on the other. Particularly, an investigation of intracellular activity by Mitani and Shimokouchi (1985) revealed that stimulation of callosal projections most commonly elicited EPSPs in the contralat-

Received Dec. 12, 2014; revised March 16, 2015; accepted March 19, 2015.

Author contributions: A.A. designed research; C.R. and A.A. performed research; C.R. and A.A. analyzed data; C.R. and A.A. wrote the paper.

We thank M. Scanziani, G. Maccaferri, C. Wilson, and M. Martina for advice, encouragement, and comments on the manuscript; S. Lebby and C. Wilson for help with single cell staining; S. Huang and G. Gaufo for help with confocal imaging; F. Santamaria, C. Paladini, N. Wicha, M. Wanat, T. Troyer, S. Quraishi, and H. Adesnik for helpful discussions; and C.A. Milam for his technical and graphical assistance.

The authors declare no competing financial interests.

Correspondence should be addressed to Dr. A. Apicella, Department of Biology, Neuroscience Institute, University of Texas at San Antonio, Biosciences Building 1.26.03, One UTSA Circle, San Antonio, TX 78249; E-mail: alfonso.apicella@utsa.edu.

DOI:10.1523/JNEUROSCI.5049-14.2015

Copyright $\odot 2015$ the authors $\quad 0270-6474 / 15 / 356703-11 \$ 15.00 / 0$ eral AC. This predicted that the loss of AC-callosal input would result in decreased activity in contralateral auditory neurons, which was recently demonstrated by Carrasco et al. (2013). However, this was inconsistent with the results of Kitzes and Doherty (1994), who reported that activation of callosal projections can have complex effects on extracellularly recorded acoustically evoked responses because they observed: suppression, excitation, and a mixed class consisting of both suppression and excitation. Despite these investigations, a detailed understanding of the circuit mechanisms by which callosal projections modulate auditory processing is still lacking. In particular, the relative impact of callosal projections onto interneurons compared with different subtypes of pyramidal neurons has not been described.

Anatomical studies have demonstrated that callosal projections are formed by a heterogeneous class of commissural neurons in placental mammals (for review, see Fame et al., 2011). The axons of callosal-projecting neurons terminate throughout all layers of the contralateral cortex, with the largest density of axonal terminals in layer $2 / 3$, and to a somewhat lesser extent layer 5 , and the lowest density of axonal terminals in layer 4 (Kelly and Wong, 1981; Code and Winer, 1986; Aitkin et al., 1988). Although layer $2 / 3$ is the dominant layer both receiving and sending interhemispheric projections in the AC, we focused our study on layer 5 because it is the main output layer of the neocortex and also because layer 5 pyramidal neurons play an important role in modulating auditory information (Bajo et al., 2010; Znamenskiy and Zador, 2013). Given the large diversity of layer 5 pyramidal neurons and their role in modulating auditory processing, determining the functional connectivity of callosal projections onto these neurons is critical for understanding the processing of acoustic signals at both cortical and subcortical levels.

Layer 5 of the AC is characterized by at least two distinct types of pyramidal neurons: corticocortical (CCort) and corticocol- 
licular (CCol). CCort pyramidal neurons project to the contralateral $\mathrm{AC}$ and striatum and they appear to modulate the interhemispheric processing of acoustic signals as well as auditory-dependent decision making (Znamenskiy and Zador, 2013). In contrast, CCol pyramidal neurons project subcortically to the inferior colliculus (IC) and appear to be involved in learning-induced auditory plasticity (Bajo et al., 2010).

Here, we test the hypothesis that callosal projections to layer 5 of the AC functionally affect specific microcircuits that can mediate both overall excitation and inhibition. In particular, we address the critical questions of whether callosal inputs result in cell-type-specific recruitment/suppression of firing in CCort versus CCol pyramidal neurons and of what type of inhibitory GABAergic neurons may be involved.

Our results show for the first time that callosal projections have opposing functional effects on CCort pyramidal neurons [direct excitation and feedforward inhibition: callosal projections $\rightarrow$ fast-spiking parvalbumin interneurons (FS-PARV) $\rightarrow$ CCort] compared with CCol pyramidal neurons [exclusively direct excitation: callosal projections $\rightarrow \mathrm{CCol}]$.

\section{Materials and Methods}

\section{Procedures}

Animal procedures were approved by the Institutional Animal Care and Use Program at the University of Texas at San Antonio and followed animal welfare guidelines from the National Institutes of Health.

\section{Mouse lines}

The following mouse lines were used in this study: wild-type (C57BL/6;

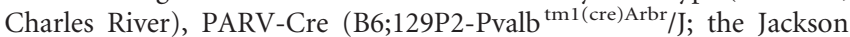
Laboratory stock number 008069), and tdTomato reporter (B6.CG.Gt

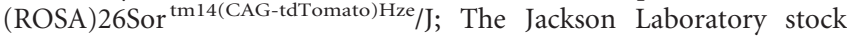
number 007914).

\section{Stereotaxic injections}

Retrograde labeling. To identify CCort and CCol pyramidal neurons, adult male mice (5-7 weeks old) were anesthetized with isoflurane (1$2.5 \%$ ) and injected with fluorescent microspheres (RetroBeads; Lumafluor) or CTB-647 (cholera toxin subunit B, recombinant, Alexa Fluor 647 conjugate; Life Technologies). Contralaterally projecting CCort pyramidal neurons were labeled by stereotaxically $(2.5 \mathrm{~mm}$ posterior from bregma, $4.25 \mathrm{~mm}$ lateral from midline; Kopf Instruments model 1900) pressure injecting (Nanoject II; Drummond Scientific) a retrograde tracer in the right AC. A borosilicate glass injection pipette (Wiretrol II; Drummond Scientific) pulled to a taper length of $\sim 30 \mathrm{~mm}$ and a tip diameter of $\sim 50 \mu \mathrm{m}$ was positioned onto the right $\mathrm{AC}$ and advanced to an injection depth of $0.9-1.2 \mathrm{~mm}$ from the surface of the brain. CCol pyramidal neurons were labeled by stereotaxically $(1.0 \mathrm{~mm}$ posterior to lambda, $1.0 \mathrm{~mm}$ lateral from midline) pressure injecting a retrograde tracer in the left IC. A borosilicate glass injection pipette pulled to a taper length of $\sim 30 \mathrm{~mm}$ and a tip diameter of $\sim 50 \mu \mathrm{m}$ was positioned onto the left IC and advanced to multiple injection depths between 1.0 and 0.5 $\mathrm{mm}$ from the surface of the brain. For each injection, $\sim 50 \mathrm{nl}$ of the tracer was delivered over a time span of 5-10 min, with the pipette remaining in place for an additional 5-10 min before being withdrawn.

Viral injections. Adeno-associated viruses (AAVs) for channelrhodopsin2 (ChR2) and halorhodopsin (Halo) were acquired from either the University of Pennsylvania Viral Vector Core or the University of North Carolina at Chapel Hill Vector Core: AAV9. CAG.hChR2.tdTomato (University of North Carolina Vector Core); AAV1.CAGGS.Flex.ChR2.tdTomato.WPRE.SV40 (Addgene 18917, UPenn Vector Core); AAV9.EFla.DIO.eNpHR3.0-eYFP.WPRE.hGH; (Addgene 26966, UPenn Vector Core).

Wild-type (male), PARV-Cre, and PARV-tdTom mice (of either sex) were injected using the same general procedures as described below. Wild-type mice $(4-5$ weeks old) were injected with AAV9.CAG.hChR2.tdTomato mixed with a tracer (RetroBeads or CTB-
647; 5:1 ratio) into the right $\mathrm{AC}$ and green or red RetroBeads into the left IC. PARV-Cre mice (4-5 weeks old) were injected with AAV1. CAGGS.Flex.ChR2-tdTomato.WPRE.SV40 into the left AC and with green or red RetroBeads into the left IC and right AC, respectively. Other PARV-Cre mice (4-5 weeks old) were simultaneously injected with AAV9.CAG.hChR2.tdTomato mixed with CTB-647 into the right AC, AAV9.EF1a.DIO.eNpHR3.0-eYFP.WPRE.hGH into the left AC and green RetroBeads into the left IC. PARV-tdTom mice (4-5 weeks old) were injected with AAV9.CAG.hChR2.tdTomato mixed with CTB-647 into the right $\mathrm{AC}$ and green RetroBeads into the left IC.

\section{In vitro slice preparation and recordings}

Two to four weeks after the intracranial injections, mice (6-9 weeks old) were anesthetized with isoflurane and decapitated. The brains of the animals were dissected and sectioned in a chilled cutting solution containing the following (in $\mathrm{mm}$ ): 110 choline chloride, $25 \mathrm{NaHCO}_{3}, 2.5$ $\mathrm{KCl}, 1.25 \mathrm{NaH}_{2} \mathrm{PO}_{4}, 0.5 \mathrm{CaCl}_{2}, 7 \mathrm{MgSO}_{4}, 25$ [sca]d-glucose, 11.6 sodium ascorbate, and 3.1 sodium pyruvate. Coronal slices containing the primary AC (300 $\mu \mathrm{m}$, bregma -2.2 to -3.1$)$ were made using a vibratome (Leica VT1200S). Slices were incubated in oxygenated artificial CSF (ACSF) solution containing the following (in mM): $126 \mathrm{NaCl}, 2.5 \mathrm{KCl}, 26$ $\mathrm{NaHCO}_{3}, 2 \mathrm{CaCl}_{2}, 1 \mathrm{MgCl}_{2}, 1.25 \mathrm{NaH}_{2} \mathrm{PO}_{4}$, and 10 D-glucose in a submerged chamber at $35-37^{\circ} \mathrm{C}$ for $30 \mathrm{~min}$ and then at room temperature $\left(21-25^{\circ} \mathrm{C}\right)$ until used for recordings.

The AC was identified by the co-presence of fluorescent axons, tracers, and axonal terminals at the injection site and projection targets including ipsilateral medial geniculate body and contralateral cortex (Xiong et al., 2012). We also used two landmarks similar to the ones used in a previous study (Oviedo et al., 2010). Briefly, we centered the $x$-axis on the boundary between the dorsal and ventral division of the lateral geniculate body, then a perpendicular line, the $y$-axis, was drawn using custom software to align the layer 5 of the AC from mouse to mouse.

Whole-cell recordings of excitatory or inhibitory inputs in voltageclamp mode were performed at $31-33^{\circ} \mathrm{C}$ in ASCF solution using pipettes with 3-4 $\mathrm{M} \Omega$ resistance. Excitatory inputs were recorded at $-70 \mathrm{mV}$ (the calculated reversal potential for GABAergic inhibitory conductances) with either K-based intracellular solution containing the following (in $\mathrm{mm}$ ): $20 \mathrm{KCl}, 120$ potassium gluconate, 10 HEPES, 0.2 EGTA, 4 ATP, 0.3 GTP, $10 \mathrm{~mm}$ phosphocreatine, and either $0 \%$ or $0.3-0.5 \%$ biocytin, or Cs-based intracellular solution containing the following (in $\mathrm{mM}$ ): 110 D-gluconic acid, $110 \mathrm{CsOH}, 10 \mathrm{Cs} \mathrm{Cl}_{2}, 1$ EGTA, 10 HEPES, 1 ATP, $10 \mathrm{~mm}$ phosphocreatine, and either 0 or $0.3-0.5 \%$ biocytin. Inhibitory inputs were recorded at $+10 \mathrm{mV}$ (the calculated reversal potential for glutamatergic excitatory conductances) with Cs-based intracellular solution. Cell-attached recording and intrinsic properties were performed using a $\mathrm{K}$-based intracellular solution at $31-33^{\circ} \mathrm{C}$. Signals were filtered at $4 \mathrm{kHz}$ and sampled at $10 \mathrm{kHz}$. Drugs used were CPP ( $5 \mu \mathrm{M}$; Tocris Bioscience), $\operatorname{NBQX}(10 \mu \mathrm{M} ; \mathrm{Abcam})$, and TTX (1 $\mu \mathrm{M} ; \mathrm{Abcam})$. The software program Ephus (Suter et al., 2010; www.ephus.org) was used for hardware control and data acquisition.

\section{ChR2 photostimulation}

Excitatory and inhibitory synaptic responses during photoactivation of the ChR2-positive callosal projections were recorded in voltage-clamp mode. Because of variability both in ChR2 expression levels (number of ChR2 molecules per transfected neuron) and transfection efficiency (number of ChR2-expressing neurons per animal), we empirically determined a suitable power for each slice using a $470 \mathrm{~nm}$ wavelength LED (CoolLED $p$ E excitation system) through a GFP filter cube (Endow GFP/ EGFP longpass, C-156625; Chroma) and a $4 \times$ or $60 \times$ water-immersion objective; this power was used for all cells recorded in the same slice. Specifically, we first patched a layer 5 CCort pyramidal neuron, adjusted the $470 \mathrm{~nm}$ wavelength LED power to record at $-70 \mathrm{mV}$ an excitatory input of $\sim 100-200 \mathrm{pA}$ peak amplitude after stimulation, and then obtained EPSC $(-70 \mathrm{mV})$ and IPSC $(+10 \mathrm{mV})$ responses at this power level. Next, we patched a CCol pyramidal neuron in the same slice located in layer 5 and acquired EPSC $(-70 \mathrm{mV})$ and IPSC $(+10 \mathrm{mV})$ responses at the same power. The order of recorded neurons was alternated between slices. Action potentials during photoactivation of the ChR2- 
positive callosal projections were recorded in both voltage-clamp and current-clamp mode using K-based intracellular solution at $31-33^{\circ} \mathrm{C}$ in ASCF solution. We first patched a layer 5 FS-PARV interneuron and adjusted the $470 \mathrm{~nm}$ wavelength LED power to elicit an action potential after stimulation. Next, we patched a CCort and a CCol pyramidal neuron in the same slice located in layer 5 and acquired a neuronal response at the same power.

\section{Simultaneous silencing of FS-PARV interneurons and activation} of callosal projections

Halorhodopsin (Halo) was conditionally expressed in FS-PARV interneurons by injecting AAV9.EF1a.DIO.eNpHR3.0-eYFP.WPRE.hGH into left AC of PARV-Cre mice. Simultaneously, these mice were injected with AAV9.CAG.hChR2.tdTomato mixed with CTB-647 into the right $\mathrm{AC}$ and with green RetroBeads into the left IC. To activate Halo, we used a $565 \mathrm{~nm}$ wavelength LED (CoolLED $p$ E excitation system) through an enhanced silver mirror mounted in a filter cube (CS190860; Chroma) and a $60 \times$ water-immersion objective. To activate ChR2, we used a 470 $\mathrm{nm}$ wavelength LED (CoolLED $p$ E excitation system) through the same enhanced silver mirror mounted used to activate Halo and a $60 \times$ waterimmersion objective. Because of variability both in ChR2 and Halo expression levels (number of ChR2 and Halo molecules per transfected neuron) and transfection efficiency (number of ChR2-expressing neurons and Halo-expressing FS-PARV interneurons per animal), we determined empirically a suitable power for each slice and used this for all cells recorded in the same slice. Specifically, we first patched a layer 5 Halopositive FS-PARV interneuron, adjusted the $470 \mathrm{~nm}$ wavelength LED power to record in cell-attached mode an action potential after stimulation, and then adjusted the $565 \mathrm{~nm}$ wavelength LED power to silence the action potential during $470 \mathrm{~nm}$ wavelength LED stimulation.

Next, we patched a CCort pyramidal neuron in the same slice located in layer 5 and acquired, while using both the $470 \mathrm{~nm}$ wavelength LED alone and the $470 \mathrm{~nm}$ plus $565 \mathrm{~nm}$ wavelength LED stimulation, excitatory $(-70 \mathrm{mV})$, and inhibitory $(+10 \mathrm{mV})$ synaptic responses at the same power.

\section{Histology}

Biocytin-filled pyramidal neurons and interneurons were patched with pipettes containing $0.3-0.5 \%$ biocytin in the internal solution. Filled neurons were held for 20-40 min and immediately fixed in formalin solution (neutral buffered, 10\% solution; Sigma-Aldrich) for several days. The slices were then washed extensively with PBS and placed in a streptavidin (Alexa Fluor 594 conjugate; Life Technologies) solution (1 $\mathrm{ml}$ of $0.3 \%$ Triton X-100 in PBS, $4 \mu \mathrm{l}$ of streptavidin). After a $2 \mathrm{~h}$ incubation period, the slices were washed in PBS and mounted with Fluoromount-G (SouthernBiotech) on a glass slide. Images were taken with a Zeiss (LSM-710) confocal microscope at 10-20× magnification.

\section{Data analysis}

Error bars in all figures represent SEM. Data and statistic analysis was performed offline using MATLAB routines (The MathWorks). Group data represent the mean \pm SEM. Group comparisons made using a Student's $t$ test if the data were normally distributed (assessed with Lilliefors' test) and rank-sum statistical tests for non-normally distributed data, with significance defined as $p<0.05$.

\section{Results \\ Morphological and electrical properties of CCort and CCol pyramidal neurons in layer 5 of the mouse AC}

To identify CCort and CCol pyramidal neurons in the left AC, we injected retrograde tracers (Fig. 1A) such as red and green microspheres into the right AC and left IC. CCort pyramidal neurons were present in layers $2 / 3,5$, and 6 , and CCol pyramidal neurons were located in layers 5 and 6 (Fig. 1B). Therefore, retrograde labeling allowed us to distinguish and record from visually identified layer 5 CCort and CCol pyramidal neurons (Fig. 1C). CCol pyramidal neurons had extensive dendritic arborization in layer 1 (Fig. 1D), a feature typical of thick-tufted pyramidal neurons in other cortical areas, whereas CCort pyramidal neurons lacked this feature (Fig. 1D) and resembled previously described thintufted pyramidal neurons (Landry et al., 1984; Cowan and Wilson, 1994; Markram, 1997; Robinson and Siegelbaum, 2003; Hattox and Nelson, 2007; Groh et al., 2010; Sheets et al., 2011; Stebbings et al., 2014). CCort pyramidal neurons exhibited a lack of "sag" of the membrane potential produced by injection of hyperpolarizing current compared with CCol pyramidal neurons (Stafstrom et al., 1982; CCort: $4.99 \pm 1.01 \% V_{\text {sag }} n=11$; CCol: $19.21 \pm 1.05 \% V_{\text {sag }}, n=13, p=3.8 \times 10^{-5}$, rank-sum test; Fig. $1 E, F)$. CCort pyramidal neurons exhibited regular-spiking firing with low-to-no adaptation after an initial doublet of action potentials, whereas CCol pyramidal neurons typically fired in bursts (11 of 13 CCol pyramidal neurons) during prolonged current steps (Fig. 1E). Further measurement of the intrinsic electrophysiological properties indicate that CCol pyramidal neurons were resting at a higher membrane potential (CCort: $-74.30 \pm 1.81$ $\mathrm{mV}, n=11$; CCol: $-69.98 \pm 0.93 \mathrm{mV}, n=13 ; p=0.04, t$ test $)$, had a lower input resistance (CCort: $126.81 \pm 9.71 \mathrm{M} \Omega, n=11$; CCol: $78.46 \pm 4.98 \mathrm{M} \Omega, n=13 ; p=0.001, t$ test), and had a shorter action potential half-width (CCort: $0.67 \pm 0.02 \mathrm{~ms}, n=$ 11; CCol: $0.57 \pm 0.02 \mathrm{~ms}, n=13 ; p=0.006$, $t$ test $)$ compared with CCort pyramidal neurons (Fig. 1E). These data show that these two distinct populations of projecting neurons can be routinely differentiated in layer 5 of AC by laminar distribution, morphology, and intrinsic electrophysiological properties.

\section{Callosal projections differentially affect the output of layer 5 CCort and CCol pyramidal neurons}

To determine how callosal projections affect the output of layer 5 CCort and CCol pyramidal neurons, we performed viral injection of $\mathrm{ChR} 2$ and red beads into the right $\mathrm{AC}$ and green beads into the left IC (Fig. 2A). After 2-3 weeks, we recorded from the left $\mathrm{AC}$, in which $\mathrm{ChR} 2$-positive axons projecting callosally from the contralateral AC could be observed in all layers (Fig. 2B). These axons have been reported to remain photoexcitable even when severed from their parent somata (Petreanu et al., 2007; Petreanu et al., 2009). Because of variability of ChR2 expression levels (number of ChR2 molecules per transfected neuron), transfection efficiency (number of ChR2-expressing neurons per ani$\mathrm{mal}$ ), and the different laminar distribution of transfected axons, we recorded in each slice from CCort and CCol pyramidal neurons located in layer 5 within $100 \mu \mathrm{m}$ from each another (see Materials and Methods). We obtained whole-cell recordings from bead-labeled CCort and CCol pyramidal neurons while injecting a step of current around the neuron's rheobase, causing the neurons to spike (Fig. 2C,D). To determine the effect of callosal projections on the output of both subtypes of pyramidal neurons, we photoactivated ChR2-positive callosal axons by flashing blue light ( $470 \mathrm{~nm}$ ) for 2-20 ms (starting 5-10 ms before the current step). Combining current injection with photoactivation of callosal projections accelerated the current-evoked action potentials in CCol pyramidal neurons (CCol current-evoked AP onset: $8.2 \pm 0.4 \mathrm{~ms}, n=10$; CCol current- plus photoactivation-evoked AP onset: $6.1 \pm 0.4 \mathrm{~ms}, n=10$; $p=$ 0.002 , rank-sum test), but abolished the action potentials in CCort pyramidal neurons (Fig. 2C,D). To establish that the silencing of the current-evoked action potentials in CCort pyramidal neurons by photoactivation of callosal projections was due to the engagement of local inhibitory circuitry, we applied gabazine $(10 \mu \mathrm{M}, n=5)$. This pharmacological application rescued the current-evoked action potentials and resulted in an acceleration of the action potential onset (CCort current-evoked AP onset: $9.4 \pm 0.3 \mathrm{~ms}, n=5$; CCort current- plus photoactivation-evoked 
A
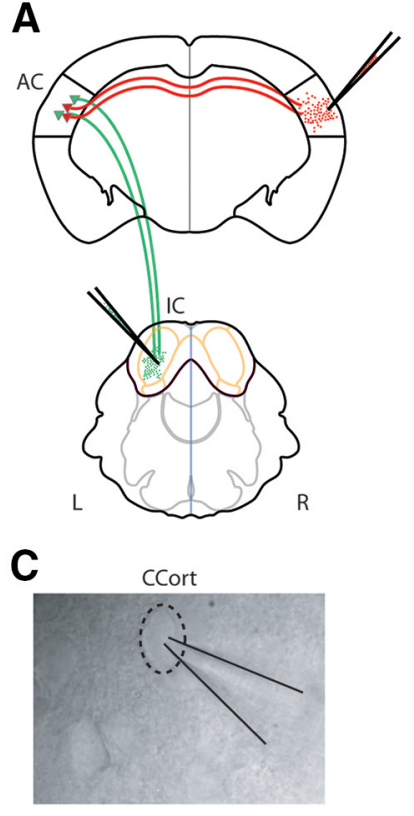

$\mathrm{BF}$

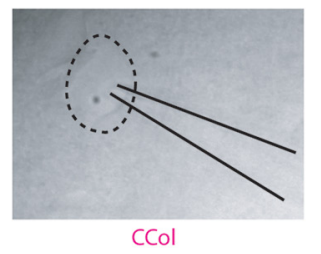

D

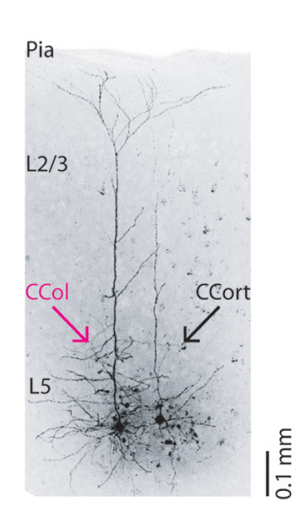

$\mathbf{F}$

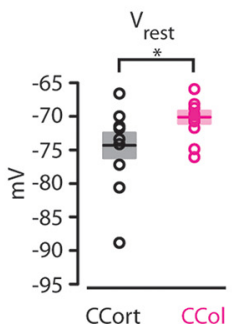

E
B
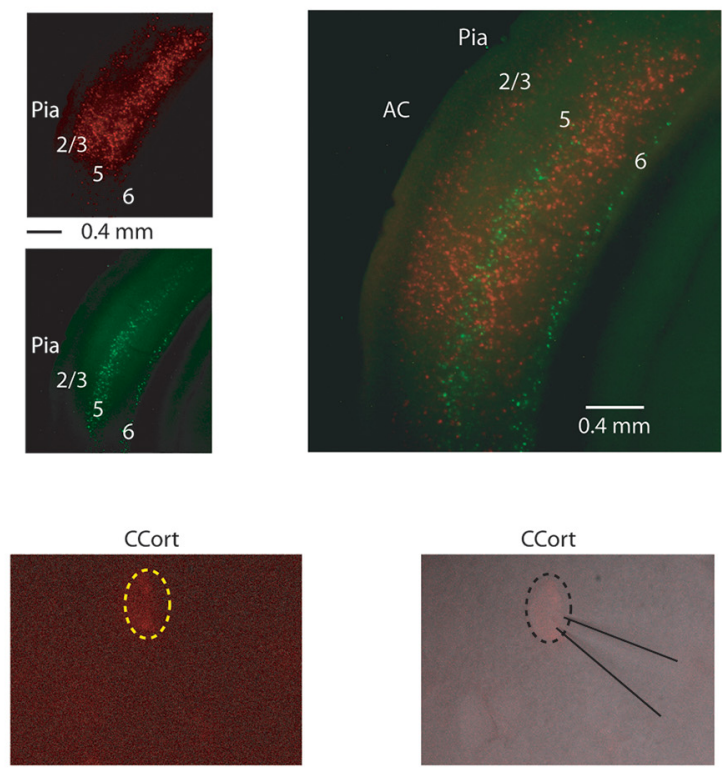

Epi

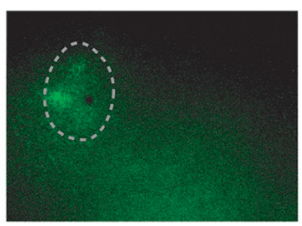

$\mathrm{CCOl}$
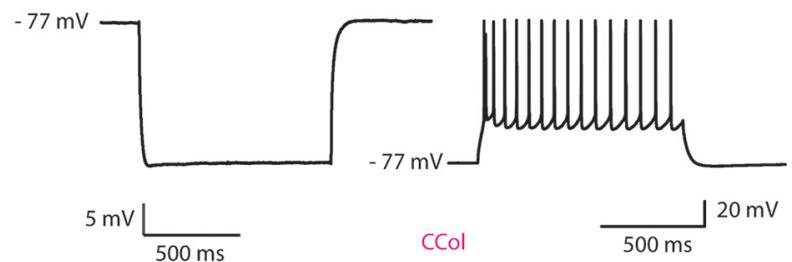

cCol

$500 \mathrm{~ms}$
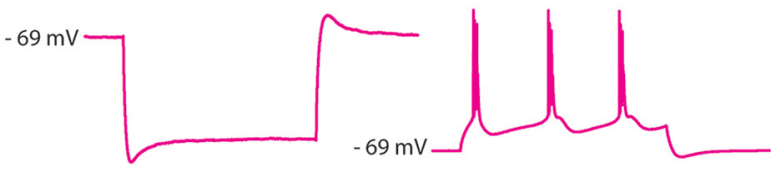

$\mathrm{AP}$ onset in the presence of gabazine: $2.9 \pm 0.7 \mathrm{~ms}, n=5 ; p=4 \times 10^{-5}$, ranksum test; Fig. 2C), similarly to the effect observed on CCol neurons in the absence of gabazine (Fig. 2D). These data indicate that callosal projections can selectively suppress action potentials in CCort, but not in CCol pyramidal neurons in layers 5 of the AC.

\section{Callosal disynaptic inhibition of CCort} and CCol pyramidal neurons

The finding that callosal projections strongly suppress CCort but not CCol pyramidal neurons in layer 5 of the AC suggested the possibility that these neurons receive different levels of excitatory and inhibitory synaptic input driven by callosal projections. To test this hypothesis, EPSCs and IPSCs were recorded in retrogradely labeled CCort and CCol pyramidal neurons during photoactivation of callosal projections (Fig. $3 A$ ). As described in the previous paragraph, because of the variability of ChR2 expression levels, transfection efficiency, and the different laminar distributions of transfected axons, we determined empirically the location of the serially recorded CCort and CCol pyramidal neurons for each slice. The soma location was measured as the normalized distance between the pia and the white matter. Particularly, the soma locations of patched neurons in the cortical column were not significantly different from each other (normalized distance from the pia, CCort: $0.67 \pm 0.02, n=14$; CCol: $0.66 \pm 0.01, n=14 ; p=0.4$, ranksum test; Fig. 3B). EPSCs and IPSCs were separated by applying a command potential of either $-70 \mathrm{mV}$ (the calculated reversal potential for GABAergic inhibitory conductance) or $+10 \mathrm{mV}$ (the calculated reversal potential for glutamatergic excitatory conductance; Fig. $3 C, E$ ). The onset of the IPSCs followed that of the EPSCs
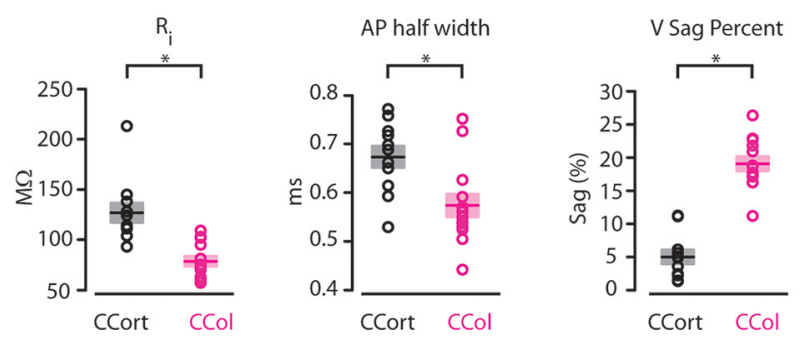

Figure 1. Morphological and electrical properties of CCort and CCol pyramidal neurons in layer 5 of the mouse primary AC. $A$, Schematic depicting injection sites to identify CCort and CCol pyramidal neurons by anatomical retrograde labeling (right AC: red RetroBeads; left IC: green RetroBeads). B, Left, Epifluorescence images of laminar distribution of CCort (top) and CCol (bottom) pyramidal neurons identified by anatomical retrograde labeling. Right, Overlay of red (CCort pyramidal neurons) and green RetroBeads (CCol pyramidal neurons). Note that the two subtypes of long-range-projecting pyramidal neurons have different laminar distribution with no overlap when located in the same lamina. C, Bright-field (top left), epifluorescence (top middle), and merged (top right) images of CCort pyramidal neurons during patch recordings. Bright-field (bottom left), epifluorescence (bottom

$\leftarrow$

middle), merged (bottom right) images of CCol pyramidal neurons during patch recordings. $\boldsymbol{D}$, High-resolution image of biocytin-labeled CCort and CCol pyramidal neurons. $E$, Response recorded from CCort (top left, black trace, $n=11$; animals $n=5$ ) and CCol (bottom left, magenta trace, $n=13$; animals $n=5)$ during injection of a hyperpolarizing current (1 $\mathrm{s},-200 \mathrm{pA}$ pulse). Train of action potentials recorded in CCort (top right, black trace, $n=11$; animals $n=5$ ) and CCol (bottom right, magenta trace, $n=13$; animals $n=5$ ) during step current injection (1s, $250 \mathrm{pA}$ pulse). $\boldsymbol{F}$, Summary plot of resting membrane potential $\left(V_{\text {rest }}\right)$, input resistance $\left(R_{\mathrm{i}}\right)$, action potential (AP) half-width, and hyperpolarization-activated current $\left(I_{\mathrm{h}}\right)$ recorded from CCort (black circles, $n=11$; animals $n=5)$ and $\mathrm{CCol}$ (magenta circles, $n=13$; animals $n=5$ ) pyramidal neurons, including group averages ( \pm SEM). 
A

Left Hemisphere

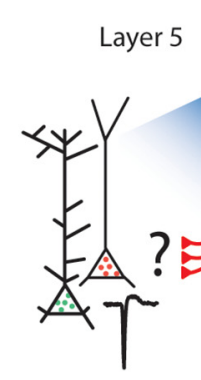

AcCort $\triangle \mathrm{ACOl}$
Right Hemisphere

B

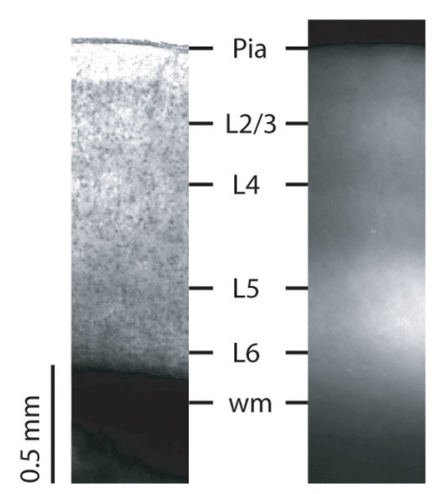

C
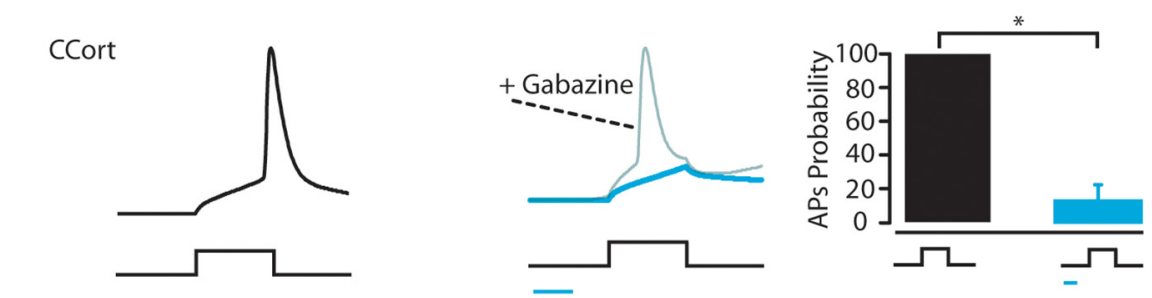

D
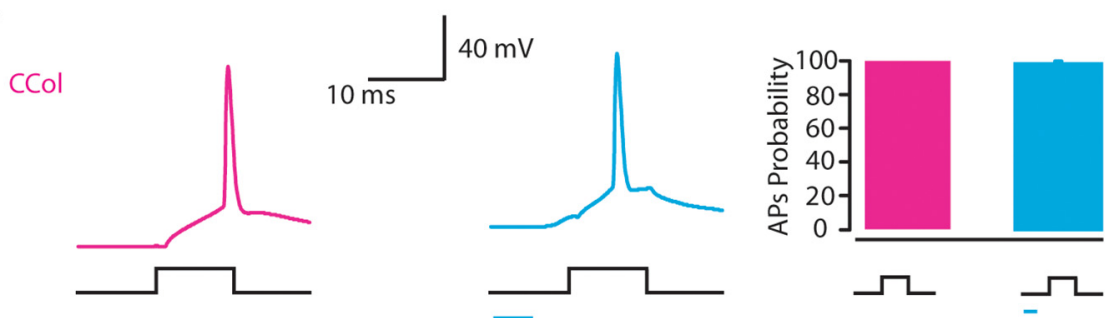

Figure 2. Photostimulation of callosal projections suppresses action potentials in CCort, but not CCol pyramidal neurons. $\boldsymbol{A}$, Experimental paradigm for photostimulating ChR2-positive callosal projections while recording from CCort and CCol pyramidal neurons identified by anatomical retrograde labeling. $\boldsymbol{B}$, Bright-field (left) and epifluorescence (right) images of a slice containing the AC showing expression of ChR2-tdTomato after injection of AAV-ChR2 into the right AC. C, Left trace, Response of a layer 5 CCort pyramidal neuron in the whole-cell current-clamp configuration to current injection (375 pA, $10 \mathrm{~ms} ; n=10$; animals $n=6)$. Middle traces, Response to current injection with photostimulation of callosal projections (blue bar 5-10 ms) and to current injection with photostimulation of callosal projections and bath application of gabazine $20 \mathrm{~mm}$. $(n=5$; animals $n=5)$. Right, Summary of ChR2-mediated action potentials suppression of CCort pyramidal neurons ( $n=10$; animals $n=6)$ during current injection and current injection combined with photostimulation of the ChR2 callosal projections. $\boldsymbol{D}$, Left trace, Response of a layer $5 \mathrm{CCol}$ pyramidal neuron in the whole-cell current-clamp configuration to current injection ( $495 \mathrm{pA}, 10 \mathrm{~ms} ; n=10$; animals $n=$ 6). Middle trace, Response to current injection with photostimulation of callosal projections (blue bar $5-10 \mathrm{~ms}$ ). Right, Summary of ChR2-mediated action potential suppressions of CCol pyramidal neurons $(n=10$; animals $n=6)$ during current injection and current injection combined with photostimulation of the ChR2 callosal projections.

with a short delay for both CCort and CCol pyramidal neurons (CCort: $1.0 \pm 0.2 \mathrm{~ms}, n=14$; CCol: $1.4 \pm 0.5 \mathrm{~ms}, n=11 ; p=0.4$, rank-sum test; Fig. $3 C-F$ ). This latency difference is consistent with the IPSCs being the result of a feedforward inhibitory network recruited by callosal projections. Blocking excitatory neurotransmission by application of glutamate receptor antagonists $\operatorname{NBQX}(10 \mu \mathrm{M})$ and CPP $(5 \mu \mathrm{M})$ abolished callosal-ChR2-evoked synaptic IPSCs (CCort: $n=5$; CCol: $n=4$; Fig. 3C,E), confirming that they were elicited by synaptic transmission. Next, we measured the amount of excitation and disynaptic inhibition experienced by CCort and CCol pyramidal neurons. CCort pyramidal neurons received significantly stronger inhibitory inputs than CCol pyramidal neurons (Fig. 3D, F, G). Both the peak IPSC amplitude (CCort: $759 \pm 170$ pA; CCol: $135 \pm 50$ pA, $n=14 ; p=$
$0.002, t$ test $)$ and inhibitory charge transfer (CCort: $17.1 \pm 3.1 \mathrm{pC}, n=14$; CCol: $6.6 \pm 1.8 \mathrm{pC}, n=14 ; p=0.005$, rank-sum test) were significantly greater in CCort than in CCol pyramidal neurons (Fig. $3 D, F, G)$. Recorded peak EPSCs amplitude was on average smaller than that of IPSCs for CCort, but not for CCol pyramidal neurons (CCort: $-248.3 \pm 47.6$ pA, $n=14$; CCol: $-87.9 \pm 22.5 \mathrm{pA}, n=$ $14 ; p=7.6 \times 10^{-6}$, rank-sum test; Fig. $3 D, F, G)$. Particularly, CCort pyramidal neurons, compared with CCol pyramidal neurons, received much more callosalChR2-evoked inhibitory than excitatory input (CCort: $\mathrm{I} / \mathrm{E}$ ratio $=3: 1, n=14$; CCol: $\mathrm{I} / \mathrm{E}$ ratio $=1.2: 1, n=14)$. In contrast, the excitatory charge transfer was not significantly different between the two subclasses of neurons (CCort: $4.1 \pm 0.5$ pC, $n=14$; CCol: $3.4 \pm 0.8$ pC, $n=14$; $p=0.5, t$ test; Fig. $3 D, F, G)$. This excitatory peak and charge dissimilarity could possibly result from differences in the distribution of the callosal excitatory inputs along the somato-dendritic compartments between CCort and CCol pyramidal neurons (Fig. 3C,E). CCort pyramidal neurons also received on average greater synaptic input, both excitatory and inhibitory, than CCol pyramidal neurons, as measured both by amplitude and charge, but similar excitatory charge (Fig. $3 G$ ). These data reveal that CCort and CCol pyramidal neurons receive a different balance of excitatory and inhibitory input driven by callosal projections.

\section{Do FS-PARV interneurons participate in callosal-driven feedforward inhibition?}

The finding that callosal projections provide direct synaptic input to CCort and CCol pyramidal neurons in layer 5 of the AC suggested the possibility that local inhibitory circuitry can also be driven synaptically by photoactivation of callosal projections (excitatory callosal projections $\rightarrow$ inhibitory interneurons $\rightarrow$ CCort pyramidal neurons; i.e., feedforward inhibition; Fig. $4 A$ ), rather than relying on feedback inhibition from local excitatory neurons. To assess this possibility, we recorded callosal-ChR2evoked action potentials in cell-attached mode, in the same slice, from retrogradely labeled CCort and CCol pyramidal neurons and genetically labeled FS-PARV interneurons (Fig. 4A). The same power and duration of blue light $(470 \mathrm{~nm})$ caused FS-PARV interneurons, but neither CCort nor CCol pyramidal neurons, to fire action potentials (FS-PARV: $n=15$; CCort: $n=9$; CCol: $n=$ 9; Fig. 4B). All recorded neurons were located within $100 \mu \mathrm{m}$ from each another. The morphological and electrical identity of patched neurons was confirmed after photostimulation by breaking in and recording the neurons' electrical properties in currentclamp mode. At the same time, neurons were filled with biocytin 
A

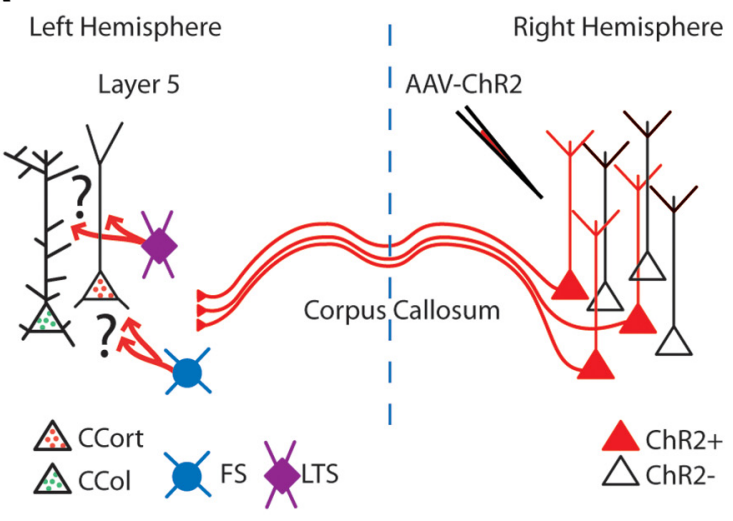

B

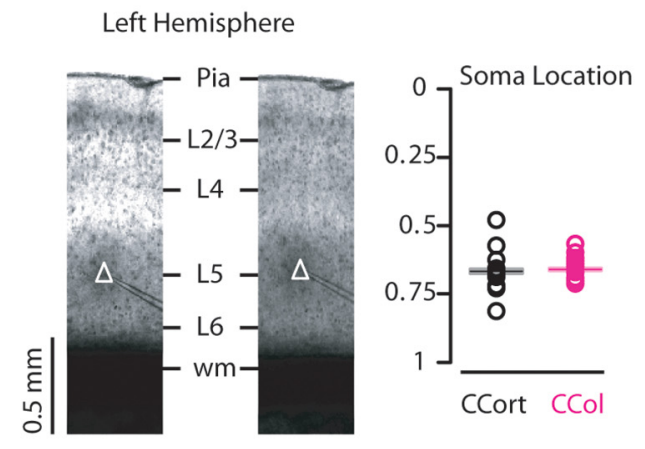

C

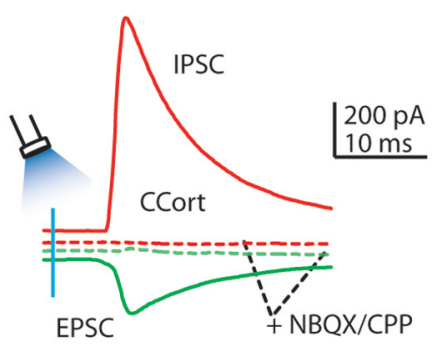

$\mathbf{E}$

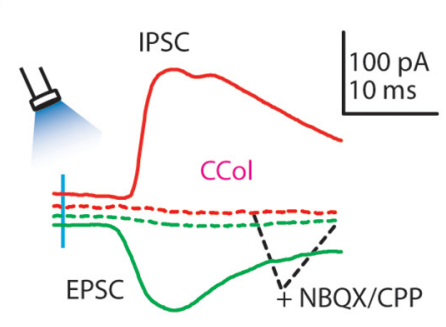

D

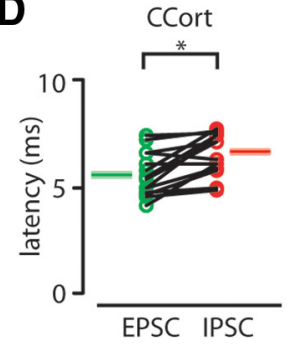

$\mathbf{F}$

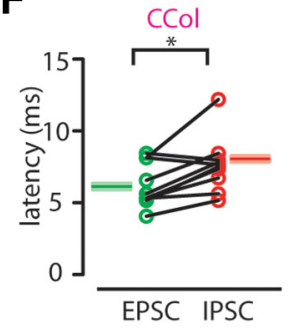

$\operatorname{IPSC}(\mathrm{pA})$
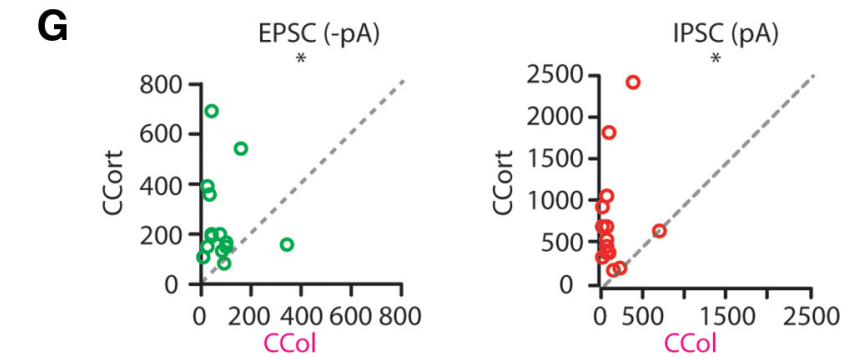
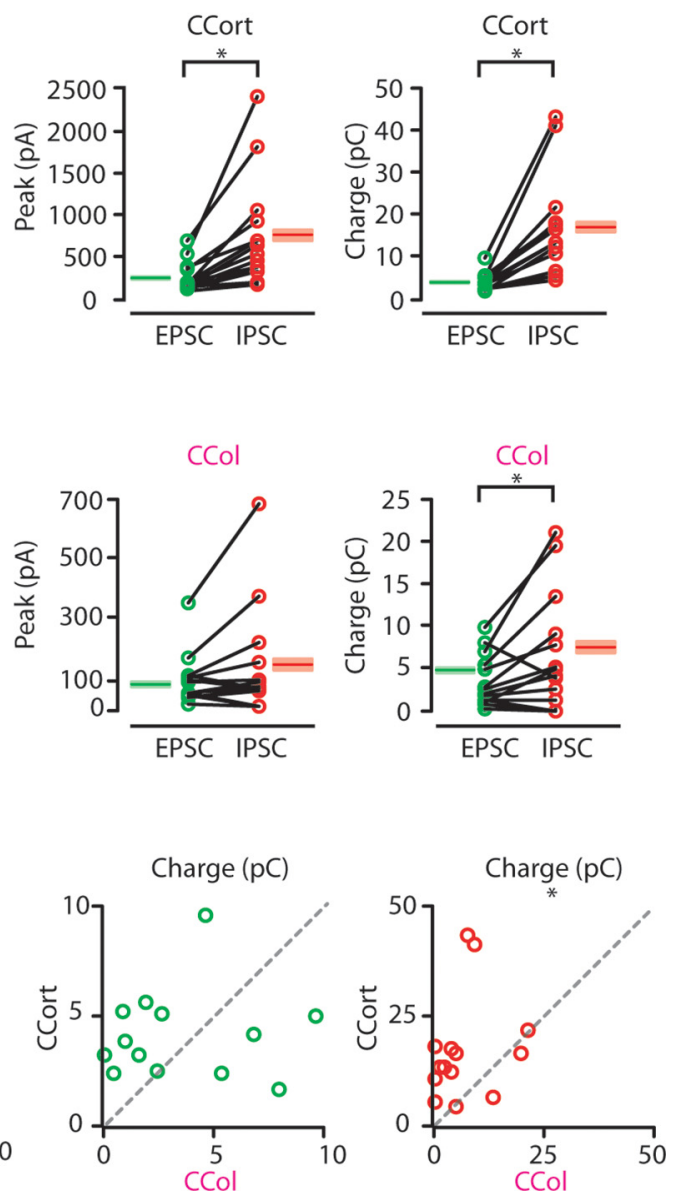

Figure 3. Photostimulation of callosal projections elicits strong disynaptic inhibition onto CCort but not onto CCol pyramidal neurons. A, Experimental paradigm for photostimulating ChR2positive callosal projections while recording excitatory and inhibitory synaptic inputs from (Cort and CCol pyramidal neurons identified by anatomical retrograde labeling. $\boldsymbol{B}$, Bright-field (left) images of a slice containing the AC showing the soma location of layer 5 CCort (right) and CCol (left) pyramidal neurons. Left plot shows the group average soma location ( \pm SEM) of CCort (black) and CCol (magenta) pyramidal neurons. Different symbols mark the absolute distances from the pia to the soma (CCort: black circles, $n=14$, animals $n=7 ;(C \operatorname{lol}$ : magenta circles, $n=14$, animals $n=7$ ). C, Examples of EPSCs (green trace) recorded at $-70 \mathrm{mV}$ and IPSCS (red trace) recorded at $+10 \mathrm{mV}$ from layer 5 CCort pyramidal neurons before and after application of ionotropic glutamate receptor antagonists (NBQX $10 \mu \mathrm{m}$, CPP $5 \mu \mathrm{m}$ : dashed green and dashed red trace). D, Left, Plot of onset latencies recorded in CCort $(n=14$; animals $n=7$ ) pyramidal neurons for EPSCS (green circles) and IPSCS (red circles), including group averages ( \pm SEM). Middle, Plot of EPSC and IPSC peaks calculated for individual EPSC-IPSC pairs for CCort pyramidal neurons, including group averages ( \pm SEM). Right, Plot of EPSC and IPSC charge transfer calculated for individual EPSC-IPSC pairs for CCort pyramidal neurons, including group averages ( \pm SEM). $E$, Same as in C but for CCol neurons ( $n=14$; animals $n=7) . \boldsymbol{F}$, Same as in $\boldsymbol{D}$ but for CCol neurons ( $n=14$; animals $n=7) . \mathbf{G}$, Summary of correlation between EPSC and IPSC peaks (left, middle left); EPSC and IPSC charge (right, middle right) calculated for individual pairs of CCort $(n=14$; animals $n=7)$ and $C \mathrm{Col}(n=14$; animals $n=7)$ pyramidal neurons during photoactivation of callosal projections.

and subsequently stained for light-microscopic morphological identification. FS-PARV interneurons morphologically resembled basket cells (5 of 5 biocytin-filled neurons; Fig. 4B). We found that the intrinsic properties of FS-PARV interneurons and CCort and CCol pyramidal neurons differed. Particularly, 3 in- trinsic properties of the FS-PARV interneurons $(n=16)$ tend to make them less excitable compared with CCort $(n=11)$ and CCol $(n=13)$ pyramidal neurons: resting membrane potentials were $\sim 4$ and $\sim 7 \mathrm{mV}$ more hyperpolarized than CCort and CCol pyramidal neurons (FS-PARV: $-76.6 \pm 1.2 \mathrm{mV}, n=16$; CCort: 


\section{A}

$$
\text { Left Hemisphere }
$$
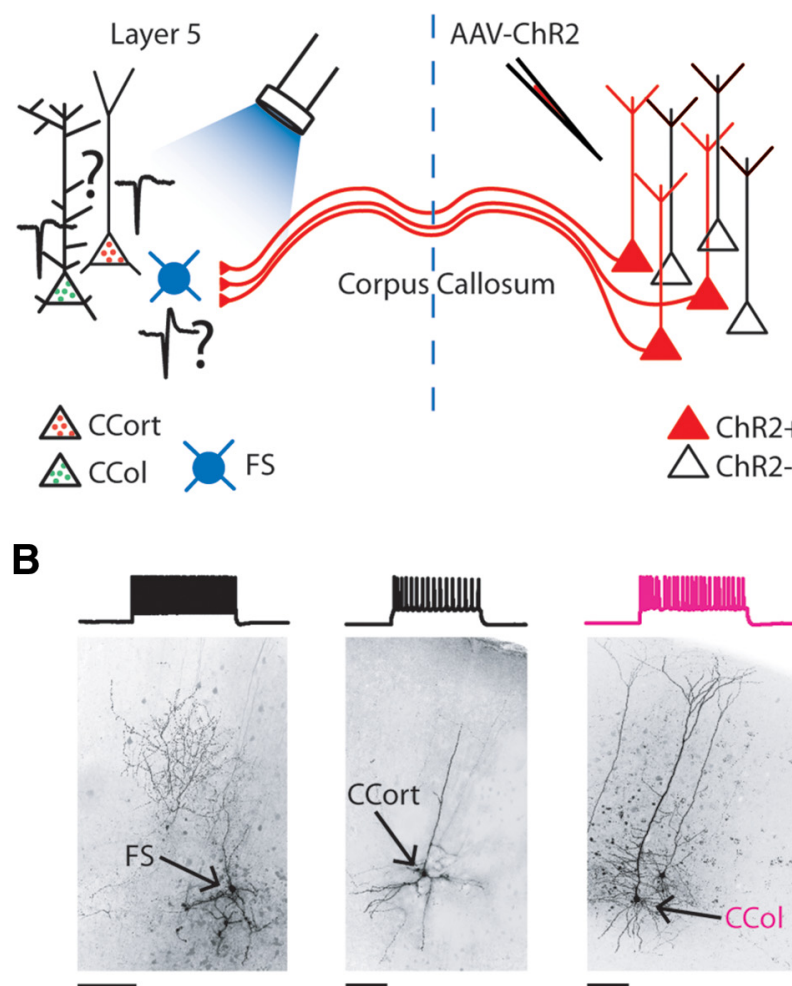

$\overline{0.1 \mathrm{~mm}}$
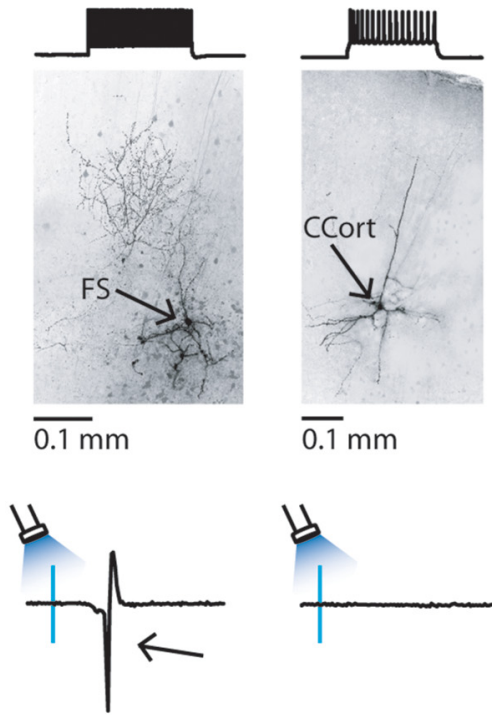

$\overline{0.1} \mathrm{~mm}$

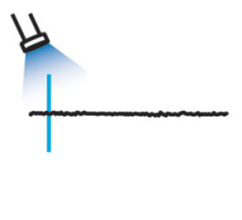

Right Hemisphere

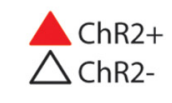

fire. These data indicate that callosal projections can drive action potentials synaptically in FS-PARV interneurons, but not in CCort and CCol pyramidal neurons in layer 5 of the AC.

\section{FS-PARV interneurons preferentially inhibit CCort pyramidal neurons}

The finding that CCort pyramidal neurons receive stronger feedforward inhibition driven by the optical stimulation of callosal projections (Fig. 3), which in turn provide strong input to synaptically drive action potentials in FS-PARV interneurons (Fig. 4 ), indicated that FS-PARV interneurons may preferentially innervate CCort pyramidal neurons (Fig. 5A). To assess this, we expressed ChR2 conditionally in the AC using viral injections of a flexed ChR2 vector (Atasoy et al., 2008) into PARV-Cre mice

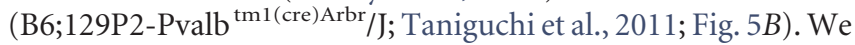
recorded, in the same slice, FS-PARV-ChR2-evoked IPSCs in retrogradely labeled CCort and CCol pyramidal neurons (Fig. 5A). Both the peak IPSC amplitude (CCort: $1247 \pm 154 \mathrm{pA}, n=14$; CCol: $837 \pm 166 \mathrm{pA}, n=14 ; p=0.04, t$ test $)$ and inhibitory charge transfer (CCort: $30.6 \pm 4.1 \mathrm{pC}, n=14$; CCol: $20.6 \pm 4.0$ $\mathrm{pC}, n=14 ; p=0.04, t$ test; Fig. $5 C$ ) were significantly greater in CCort than CCol pyramidal neurons. These data indicate that FS-PARV interneurons preferentially inhibit CCort pyramidal neurons compared with CCol pyramidal neurons in layer 5 of the AC.

\section{Suppression of CCort pyramidal neurons by FS-PARV interneurons during photoactivation of callosal projections} The disynaptic feedforward circuit we describe (callosal excitatory projections $\rightarrow$ FS-PARV inhibitory interneurons $\rightarrow$ inhibition of CCort pyramidal neurons) explains the suppression of action potentials recorded from CCort pyramidal neurons in response to photoactivation of callosal projections (Fig. 2). To test this directly, we optogenetically silenced FS-PARV interneurons while recording inhibitory input in CCort pyramidal neurons during photoactivation of callosal projections (Fig. 6A). A lightsensitive chloride ion pump, halorhodopsin (Halo; Gradinaru et al., 2008) was conditionally expressed in the AC by viral injection of a flexed Halo vector into PARV-Cre mice. Concurrently, we retrogradely labeled CCort pyramidal neurons in the AC and transfected callosal projections from the contralateral AC with ChR2 (Fig. 6A). Under these conditions, photostimulation of callosal-ChR2 projections (blue light, $470 \mathrm{~nm}$ ) can reliably drive action potentials in FS-PARV interneurons $(n=8)$. However, coactivation of both callosal-ChR2 projections ( $470 \mathrm{~nm}$ ) and FSPARV-Halo interneurons (amber light, $565 \mathrm{~nm}$ ) abolished the previously described callosal-ChR2-evoked action potentials in FS-PARV interneurons $(n=8$; Fig. $6 B$ ). Halo activation strongly hyperpolarized FS-PARV-Halo interneurons, preventing firing of action potentials in these cells. In addition, activation of Halo $(565 \mathrm{~nm})$ in these FS-PARV interneurons during a currentevoked barrage of action potentials provided strong inhibition, silencing the action potentials in the middle of the barrage $(n=5$; Fig. 6B).

Having verified that we could optogenetically suppress the activity of FS-PARV interneurons driven by callosal projections, we next investigated whether this blockade would silence callosal-ChR2-evoked IPSCs in CCort pyramidal neurons. First, we established the level of Halo activation $(565 \mathrm{~nm})$ that did not interfere with callosal-ChR2-evoked $(470 \mathrm{~nm})$ EPSCs in CCort pyramidal neurons (CCort EPSC suppression, $470 \mathrm{~nm}+565 \mathrm{~nm}$ compared with $470 \mathrm{~nm}$ alone: $0.072 \pm 0.040, n=8, p=0.3$, $t$ test; 
A

Left Hemisphere

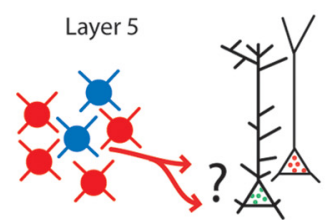

Accort $\precsim$ FSChR2+

$\triangle \mathrm{CCOl}$ FSChR2-
B

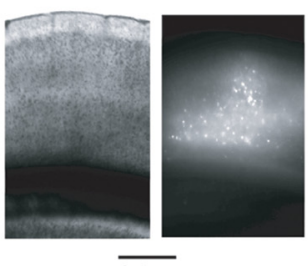

$\overline{0.4 \mathrm{~mm}}$
C

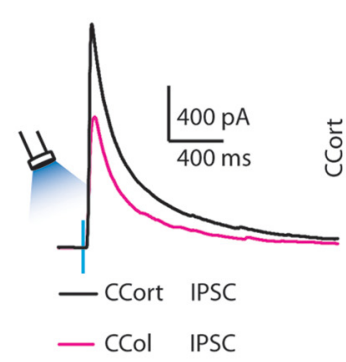

D
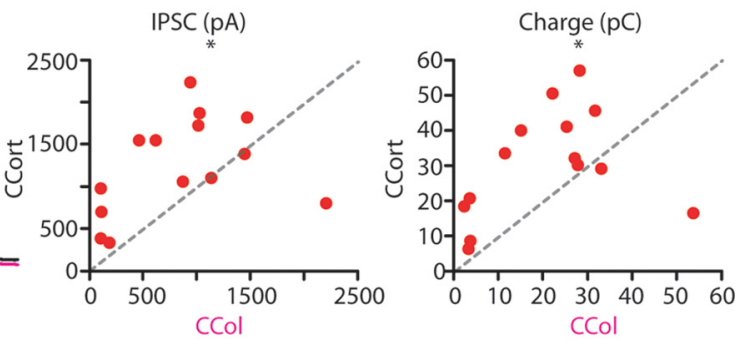

Figure 5. FS-PARV-ChR2-evoked inhibitory input onto CCort and CCol pyramidal neurons. $A$, Experimental paradigm for photostimulating FS-PARV ChR2-positive interneurons while recording IPSCs from CCort and CCol pyramidal neurons identified by anatomical retrograde labeling. $\boldsymbol{B}$, Bright-field (left) and epifluorescence (right) images of a slice containing the AC showing expression of ChR2 in FS-PARV following injection of AAV-ChR2-flex into the left AC. C, Examples of IPSCs recorded at +10 mV from a layer 5 CCort (black) and CCol (magenta) pyramidal neuron. $\boldsymbol{D}$, Plot of correlation between IPSC peaks (left) and IPSC charge (right) calculated for individual pairs of CCort and CCol pyramidal neurons while stimulating FS-PARV ChR2-positive interneurons.

Fig. $6 C, D)$. Then, in the same neurons, we recorded callosalChR2-evoked IPSCs by applying a command potential of +10 $\mathrm{mV}$ while alternating between ChR2 $(470 \mathrm{~nm})$ activation alone and coactivation of ChR2 (470 nm) and Halo (565 nm). Photohyperpolarization of FS-PARV-Halo interneurons significantly reduced callosal-ChR2-evoked IPSCs of layer 5 CCort pyramidal neurons (CCort IPSC suppression, $470 \mathrm{~nm}+565 \mathrm{~nm}$ compared with $470 \mathrm{~nm}$ alone: $0.825 \pm 0.066, n=10, p=0.004$, rank-sum test; Fig. $6 C, D)$. Moreover, photohyperpolarization of FS-PARVHalo interneurons rescued the current-evoked action potentials from CCort pyramidal neurons due to photoactivation of callosal projections $(n=5$; Fig. $6 E)$. Overall, these results provide direct evidence that excitatory input from callosal projections recruit FS-PARV interneurons and that these interneurons in turn suppress the activity of CCort pyramidal neurons via a feedforward inhibitory mechanism (callosal excitatory projections $\rightarrow$ FSPARV $\rightarrow$ CCort pyramidal neurons; Fig. 7).

\section{Discussion}

This study reveals two distinct previously unknown interhemispheric cortical circuits. The first one significantly contributes to the suppression of the excitability of layer 5 CCort, but not CCol pyramidal neurons (Figs. 2, 3). Furthermore, it also identifies a specific type of inhibitory interneuron, FS-PARV, as the fundamental intermediary of this type of inhibitory process (callosal excitatory projections $\rightarrow$ FS-PARV $\rightarrow$ CCort). The second one promotes the facilitation of the activity of CCol pyramidal neurons in layer 5 of the AC (callosal excitatory projections $\rightarrow$ CCol; Figs. 5, 6).

\section{Anatomical and functional properties of auditory callosal projections}

Anatomical studies in the cat AC, as well in other species (Ravizza et al., 1976; Cipolloni and Peters, 1983; Aitkin et al., 1988; Games and Winer, 1988; Lee and Winer, 2008), have demonstrated that auditory callosal projections pass through the splenium of the corpus callosum and terminate in the contralateral homotopic cortical field (Lomber et al., 1994; Clarke et al., 1995). In particular, callosal projections are formed by a heterogeneous class of commissural neurons in placental mammals (Aboitiz and Montiel, 2003); their somata are located predominately in layers 2-3 ( $\sim 80 \%$ in rodents), layer $5(\sim 20 \%)$, and, to a lesser extent, layer 6 (Jacobson and Trojanowski, 1974; Fame et al., 2011). The axons of callosal projecting neurons terminate throughout all layers, with the largest density of axonal terminals in supragranular and infragranular layers and the lowest density of axonal terminals in layer 4 (Code and Winer, 1986; Aitkin et al., 1988). However, despite a large amount of anatomical study, only a few studies have investigated the functional properties of callosal projections (Mitani and Shimokouchi, 1985; Mitani et al., 1985; Kitzes and Doherty, 1994; Carrasco et al., 2013). Particularly, Carrasco et al. (2013) suggested that, in the AC, neurons located in deep and superficial layers are more receptive to contralateral deactivation of callosal-projecting neurons; similar effects have been observed in the visual cortex (Payne et al., 1991). To date, no study has revealed a detailed understanding of the circuit mechanisms by which callosal projections modulate auditory processing. In this study, we have identified two distinct previously unknown interhemispheric cortical circuits that contribute to the suppression of CCort and facilitation of CCol pyramidal neurons. Particularly, one of the main findings of this study is that callosal projections exert monosynaptic excitatory input and disynaptic inhibition (Fig. 3). Our finding is consistent with previous results demonstrating that callosal projections form asymmetric synapses with dendritic spines of pyramidal neurons, suggesting the presence of excitatory projections (Cipolloni and Peters, 1983), although it contrasts with results showing the direct influences of callosally projecting non-pyramidal neurons in the cat visual cortex (Peters et al., 1990). In fact, blocking excitatory neurotransmission by application of glutamate receptor antagonists abolished callosalChR2-evoked synaptic IPSCs, confirming that they were elicited by synaptic transmission and not due to a direct photoactivation of inhibitory callosal projections. Our results extend previous observations by showing that callosal projections to layer 5 of the AC are not homogeneous, but functionally impact specific microcircuits that can mediate both overall excitation and inhibition.

\section{Local and long-range connection of CCort and CCol pyramidal neurons}

Previous studies in both sensory and motor cortex have identified differences in local connections between subtypes of layer 5 pyramidal neurons (Markram, 1997; Morishima and Kawaguchi, 2006; Brown and Hestrin, 2009a, 2009b; Dani and Nelson, 2009; Morishima et al., 2011; Apicella et al., 2012). In particular, a recent study (Sakata and Harris, 2009) observed that layer 5 thick-tufted neurons (such as CCol pyramidal neurons)-for which they observed the densest activity-received weaker inhibition than slender neurons (such as CCort pyramidal neurons) during sound stimulation. More recently, Sun et al. (2013) suggested that intrinsic bursting pyramidal neurons (such as CCol) have spectrally and temporally broader synaptic integration than regular spiking pyramidal neurons (such as CCort). Moreover, stimulation of the $\mathrm{AC}$ enhances IC neuronal response at the pre- 

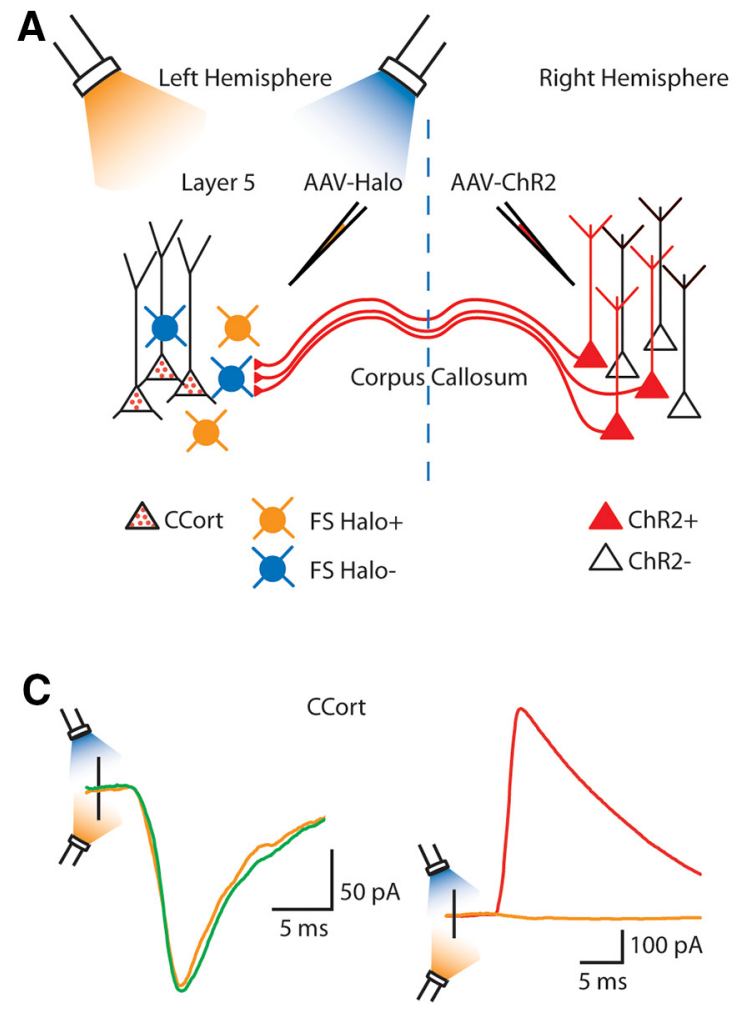

B
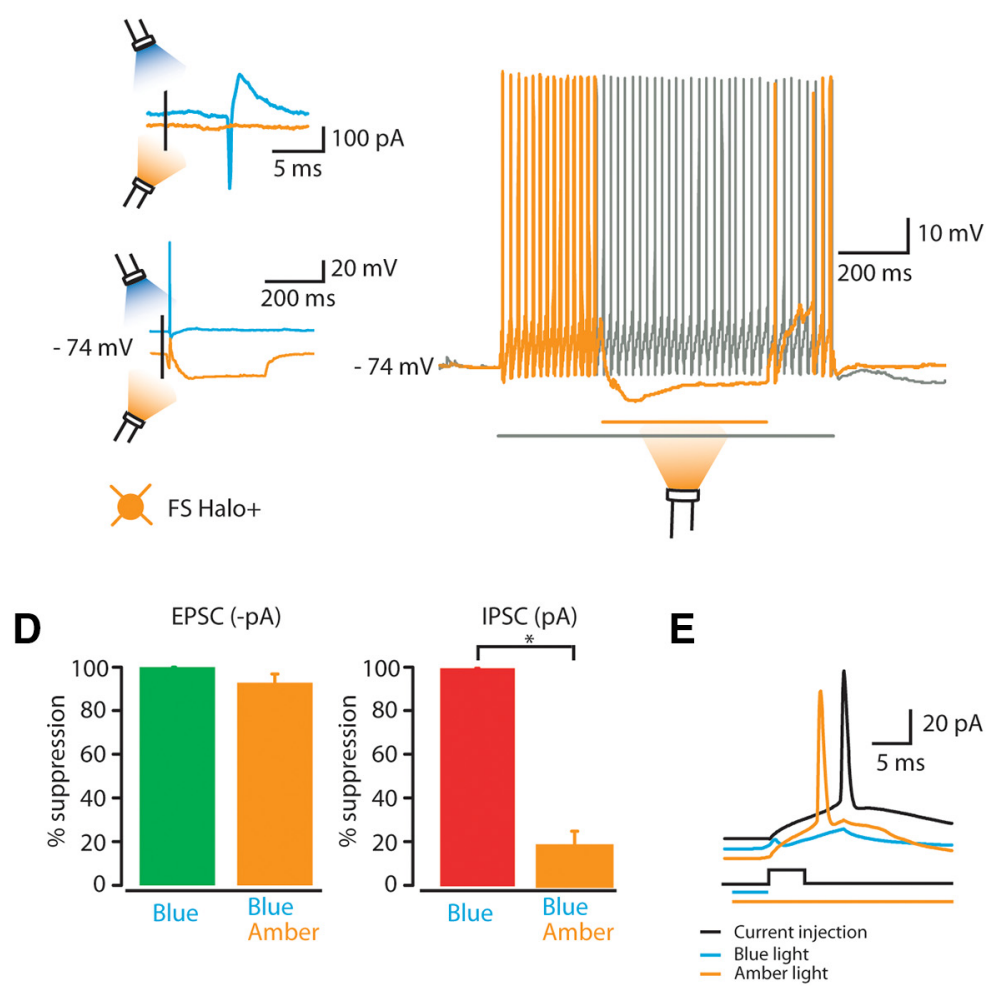

Figure 6. Suppression of CCort pyramidal neurons by FS-PARV interneurons as a function of photoactivation of callosal projections. $\boldsymbol{A}$, Experimental paradigm for photostimulating ChR2-positive callosal projections and photosilencing Halo-positive FS-PARV interneurons while recording from CCort pyramidal neurons identified by anatomical retrograde labeling after injection of AAV-ChR2 in the right AC and AAV-Halo-flex into left AC. $\boldsymbol{B}$, Left, Example showing an action potential and its suppression recorded both in cell-attached (top left, $n=8$; animals $n=8$ ) and whole-cell mode (bottom left, $n=8$; animals $n=8$ ) from a FS-PARV-Halo interneuron during photoactivation of callosal projections and during simultaneous photoactivation of callosal projections and photosilencing of the same FS-PARV-Halo interneuron. Right, Example showing photosilencing of action potentials during a current-evoked barrage of action potentials in a FS-PARV-Halo interneuron by flashing amber light $(565 \mathrm{~nm})$ in the middle of the barrage of action potentials $(n=5$; animals $n=5)$. C, Left, Examples of EPSCs recorded at $-70 \mathrm{mV}$ from layer 5 CCort pyramidal neurons during photoactivation of callosal projections (green trace, $n=8$; animals $n=8$ ) and during simultaneous photoactivation of callosal projections and photosilencing of FS-PARV-Halo interneurons (amber trace, $n=8$; animals $n=8$ ). Right, Examples of IPSCs recorded at $+10 \mathrm{mV}$ from layer 5 CCort pyramidal neurons during photoactivation of callosal projections (red trace, $n=10$; animals $n=8$ ) and during simultaneous photoactivation of callosal projections and photosilencing of FS-PARV-Halo interneurons (amber trace, $n=10$; animals $n=8$ ). $\boldsymbol{D}$, Summary plot of EPSC (left, $n=8$; animals $n=8$ ) and IPSC (right, $n=10$; animals $n=8$ ) peaks recorded from layer 5 CCort pyramidal neurons during photoactivation of callosal projections and during simultaneous photoactivation of callosal projections and photosilencing of FS-PARV-Halo interneurons. $\boldsymbol{E}$, Black trace, Response of a layer 5 CCort pyramidal neuron in the whole cell current-clamp configuration to current injection ( $385 \mathrm{pA}$, $10 \mathrm{~ms} ; n=5$; animals $n=5$ ). Blue trace, Response to current injection with photostimulation of callosal projections (blue bar $5-10 \mathrm{~ms} ; n=5$; animals $n=5$ ). Amber trace, Response to current injection with photostimulation of callosal projections and photosilencing of FS-PARV-Halo interneurons (blue bar: $5-10 \mathrm{~ms}$, amber bar: $50-100 \mathrm{~ms} ; n=5$; animals $n=5$ ).

ferred frequency of their tuning curve and inhibits at frequencies lower or higher than the preferred frequency (Sun et al., 1996; Yan and Suga, 1996). CCol synaptic contacts are also considered to be small, supporting a putative modulatory role in the IC (Saldaña et al., 1996). Our finding that callosal projections contribute to the suppression of the excitability of layer 5 CCort, but not CCol, pyramidal neurons suggests that these differences, which have been observed in local connections between subtypes of layer 5 pyramidal neurons, are also present for long-range connections.

Our results are also supported by a previous finding by Hefti and Smith (2000) that intrinsic bursting pyramidal neurons (such as CCol) receive less inhibitory input and are able to spike in response to thalamocortical stimulation far more promptly than regular spiking pyramidal neurons (such as CCort). It is possible that CCol pyramidal neurons ensure robust feedback signals to facilitate IC function critical for learning-induced localization plasticity (Bajo et al., 2010). Contrarily, based on evidence from our experiments, CCort pyramidal neurons are strongly inhibited and therefore provide less robust, but more precise, information about sensory stimuli to their synaptic targets.

\section{Inhibitory layer 5 microcircuit organization of auditory callosal projections}

Previous studies found that connections between local GABAergic interneurons and pyramidal neurons can be nonselective, meaning that interneurons have a non-preferential targeting of the nearby pyramidal neurons (Fino and Yuste, 2011; Packer and Yuste, 2011), or selective, meaning that interneurons specifically innervate pyramidal neurons that project to specific targets while sparing neighboring pyramidal neurons that project elsewhere (Fishell and Rudy, 2011; Krook-Magnuson et al., 2012; Varga et al., 2010; Lee et al., 2014b; Fariñas and DeFelipe, 1991). In the present study, we observed evidence of the latter phenomenon in layer 5 of the AC. Our finding that FS-PARV interneurons preferentially inhibit CCort pyramidal neurons provide for the first time extensive evidence for the presence of a specialized inhibitory microcircuit targeting functionally distinct subtypes of layer 5 long-range-projecting pyramidal neurons in the AC. Our results from the AC indicating selectivity of FS-PARV interneurons are consistent with data from the hippocampus (Lee et al., 2014b), neocortex (Lee et al., 2014a), and striatum (Gittis et al., 


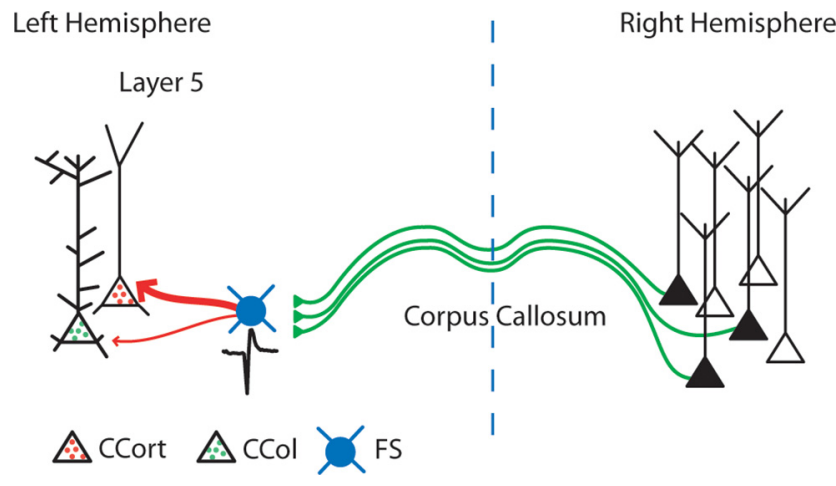

Figure 7. Model of callosal projections driving neuronal-specific responses in the mouse AC. Callosal projections suppress activity of layer 5 CCort, but not $\mathrm{CCO}$, pyramidal neurons in the $\mathrm{AC}$ by recruiting FS-PARV interneurons. Green lines, excitatory inputs; red arrows, inhibitory inputs.

2010), supporting the growing view that interneurons have the capability to selectively regulate specific information-processing streams represented by subtypes of pyramidal neurons with distinct long-range projection targets (Krook-Magnuson et al., 2012). Our finding that FS-PARV interneurons respond to callosal-projecting pyramidal neuron activity and produce feedforward somatic inhibition across the local CCort pyramidal neurons could imply a mechanism of coincidence detection (Pouille and Scanziani, 2001) in the AC. Because the homotopic projections are the strongest of all the callosal projections (Rouiller et al., 1991; Lee and Winer, 2008), the presence of feedforward inhibition may thus serve as a means to maintain timing across these areas and therefore refine sensory information about auditory stimuli between the two hemispheres. Moreover, the selective connectivity between FS-PARV interneurons and CCort pyramidal neurons also suggests a mechanism of gamma oscillations in response to callosal projections. Indeed, FS-PARV interneurons have been proposed to contribute to the phasing of pyramidal neurons during oscillations (Bartos et al., 2007; Buzsáki and Wang, 2012). Together, our results emphasize the complexity of cortical circuits recruited by callosal projections, as well as the notion that the relationship between excitation and inhibition is cell-type dependent.

\section{Layer 5 microcircuit: sound localization model}

The existence of uneven excitatory and inhibitory microcircuits between CCort and CCol pyramidal neurons and FS-PARV interneurons recruited by callosal projections is likely to have profound consequences for the interhemispheric mechanisms by which local inhibition in the AC regulates output from the cortex crucial for sound localization processes underlying spatial hearing (Poirier et al., 1995; Lepore et al., 1997; Stecker and Middlebrooks, 2003; Grothe et al., 2010).

The ability of the AC to perform sound localization processes that underlie spatial hearing depends on differences in timing and intensity for sounds arriving to the two ears, with each ear projecting predominately to the AC of the contralateral hemisphere. This, together with our finding that the action potential onset of CCol pyramidal neurons was accelerated by pairing current injection with callosal-ChR2 photoactivation, supports a new model in which CCol pyramidal neuron activity can be potentially characterized by a bilateral receptive field and could be, via callosal projections, responsible for integrating information for the two separate auditory hemifields. Therefore, callosal projections are likely responsible for ipsilateral inputs to CCol bilat- eral receptive field pyramidal neurons in layer 5 of the AC. Conversely, our finding that callosal projections can synaptically suppress action potentials in CCort pyramidal neurons suggests that their suppression via these projections is potentially responsible for disconnecting the two auditory hemifields, therefore enhancing lateral sound localization. It is probable that a callosalconnectivity pattern analogous to what is elucidated here may be present in other cortical areas as well and thus contribute to differentially unifying and disconnecting the two hemifields in several sensory modalities.

\section{References}

Aboitiz F, Montiel J (2003) One hundred million years of interhemispheric communication: the history of the corpus callosum. Braz J Med Biol Res 36:409-420. Medline

Aitkin LM, Kudo M, Irvine DR (1988) Connections of the primary auditory cortex in the common marmoset, Callithrix jacchus jacchus. J Comp Neurol 269:235-248. CrossRef Medline

Apicella AJ, Wickersham IR, Seung HS, Shepherd GM (2012) Laminarly orthogonal excitation of fast-spiking and low-threshold-spiking interneurons in mouse motor cortex. J Neurosci 32:7021-7033. CrossRef Medline

Atasoy D, Aponte Y, Su HH, Sternson SM (2008) A FLEX switch targets Channelrhodopsin-2 to multiple cell types for imaging and long-range circuit mapping. J Neurosci 28:7025-7030. CrossRef Medline

Bajo VM, Nodal FR, Moore DR, King AJ (2010) The descending corticocollicular pathway mediates learning-induced auditory plasticity. Nat Neurosci 13:253-260. CrossRef Medline

Bamiou DE, Sisodiya S, Musiek FE, Luxon LM (2007) The role of the interhemispheric pathway in hearing. Brain Res Rev 56:170-182. CrossRef Medline

Bartos M, Vida I, Jonas P (2007) Synaptic mechanisms of synchronized gamma oscillations in inhibitory interneuron networks. Nat Rev Neurosci 8:45-56. CrossRef Medline

Bloom JS, Hynd GW (2005) The role of the corpus callosum in interhemispheric transfer of information: excitation or inhibition? Neuropsychol Rev 15:59-71. CrossRef Medline

Brown SP, Hestrin S (2009a) Cell-type identity: a key to unlocking the function of neocortical circuits. Curr Opin Neurobiol 19:415-421. CrossRef Medline

Brown SP, Hestrin S (2009b) Intracortical circuits of pyramidal neurons reflect their long-range axonal targets. Nature 457:1133-1136. CrossRef Medline

Buzsáki G, Wang XJ (2012) Mechanisms of gamma oscillations. Annu Rev Neurosci 35:203-225. CrossRef Medline

Carrasco A, Brown TA, Kok MA, Chabot N, Kral A, Lomber SG (2013) Influence of core auditory cortical areas on acoustically evoked activity in contralateral primary auditory cortex. J Neurosci 33:776-789. CrossRef Medline

Cipolloni PB, Peters A (1983) The termination of callosal fibres in the auditory cortex of the rat: a combined Golgi-electron microscope and degeneration study. J Neurocytol 12:713-726. CrossRef Medline

Clarke S, de Ribaupierre F, Bajo VM, Rouiller EM, Kraftsik R (1995) The auditory pathway in cat corpus callosum. Exp Brain Res 104:534-540. CrossRef Medline

Code RA, Winer JA (1986) Columnar organization and reciprocity of commissural connections in cat primary auditory cortex (AI). Hear Res 23: 205-222. CrossRef Medline

Cowan RL, Wilson CJ (1994) Spontaneous firing patterns and axonal projections of single corticostriatal neurons in the rat medial agranular cortex. J Neurophysiol 71:17-32. Medline

Dani VS, Nelson SB (2009) Intact long-term potentiation but reduced connectivity between neocortical layer 5 pyramidal neurons in a mouse model of Rett syndrome. J Neurosci 29:11263-11270. CrossRef Medline

Fame RM, MacDonald JL, Macklis JD (2011) Development, specification, and diversity of callosal projection neurons. Trends Neurosci 34:41-50. CrossRef Medline

Fariñas I, DeFelipe J (1991) Patterns of synaptic input on corticocortical and corticothalamic cells in the cat visual cortex. II. The axon initial segment. J Comp Neurol 304:70-77. CrossRef Medline

Fino E, Yuste R (2011) Dense inhibitory connectivity in neocortex. Neuron 69:1188-1203. CrossRef Medline

Fishell G, Rudy B (2011) Mechanisms of inhibition within the telencephalon: "where the wild things are." Annu Rev Neurosci 34:535-567. CrossRef Medline 
Games KD, Winer JA (1988) Layer V in rat auditory cortex: projections to the inferior colliculus and contralateral cortex. Hear Res 34:1-25. CrossRef Medline

Gittis AH, Nelson AB, Thwin MT, Palop JJ, Kreitzer AC (2010) Distinct roles of GABAergic interneurons in the regulation of striatal output pathways. J Neurosci 30:2223-2234. CrossRef Medline

Gradinaru V, Thompson KR, Deisseroth K (2008) eNpHR: a Natronomonas halorhodopsin enhanced for optogenetic applications. Brain Cell Biol 36:129-139. CrossRef Medline

Groh A, Meyer HS, Schmidt EF, Heintz N, Sakmann B, Krieger P (2010) Cell-type specific properties of pyramidal neurons in neocortex underlying a layout that is modifiable depending on the cortical area. Cereb Cortex 20:826-836. CrossRef Medline

Grothe B, Pecka M, McAlpine D (2010) Mechanisms of sound localization in mammals. Physiol Rev 90:983-1012. CrossRef Medline

Hattox AM, Nelson SB (2007) Layer V neurons in mouse cortex projecting to different targets have distinct physiological properties. J Neurophysiol 98:3330-3340. CrossRef Medline

Hefti BJ, Smith PH (2000) Anatomy, physiology, and synaptic responses of rat layer $\mathrm{V}$ auditory cortical cells and effects of intracellular GABA(A) blockade. J Neurophysiol 83:2626-2638. Medline

Jacobson S, Trojanowski JQ (1974) The cells of origin of the corpus callosum in rat, cat and rhesus monkey. Brain Res 74:149-155. CrossRef Medline

Kelly JP, Wong D (1981) Laminar connections of the cat's auditory cortex. Brain Res 212:1-15. CrossRef Medline

Kitzes LM, Doherty D (1994) Influence of callosal activity on units in the auditory cortex of ferret (Mustela putorius). J Neurophysiol 71:17401751. Medline

Krook-Magnuson E, Varga C, Lee SH, Soltesz I (2012) New dimensions of interneuronal specialization unmasked by principal cell heterogeneity. Trends Neurosci 35:175-184. CrossRef Medline

Landry P, Wilson CJ, Kitai ST (1984) Morphological and electrophysiological characteristics of pyramidal tract neurons in the rat. Exp Brain Res 57:177-190. Medline

Lee AT, Gee SM, Vogt D, Patel T, Rubenstein JL, Sohal VS (2014a) Pyramidal neurons in prefrontal cortex receive subtype-specific forms of excitation and inhibition. Neuron 81:61-68. CrossRef Medline

Lee CC, Winer JA (2008) Connections of cat auditory cortex: II. Commissural system. J Comp Neurol 507:1901-1919. CrossRef Medline

Lee SH, Marchionni I, Bezaire M, Varga C, Danielson N, Lovett-Barron M, Losonczy A, Soltesz I (2014b) Parvalbumin-positive basket cells differentiate among hippocampal pyramidal cells. Neuron 82:1129-1144. CrossRef Medline

Lepore F, Poirier P, Provençal C, Lassonde M, Miljours S, Guillemot JP (1997) Cortical and callosal contribution to sound localization. Acoustical Signal Processing in the Central Auditory System, pp 389-398.

Lomber SG, Payne BR, Rosenquist AC (1994) The spatial relationship between the cerebral cortex and fiber trajectory through the corpus callosum of the cat. Behav Brain Res 64:25-35. CrossRef Medline

Markram H (1997) A network of tufted layer 5 pyramidal neurons. Cereb Cortex 7:523-533. CrossRef Medline

Mitani A, Shimokouchi M (1985) Neuronal connections in the primary auditory cortex: an electrophysiological study in the cat. J Comp Neurol 235:417-429. CrossRef Medline

Mitani A, Shimokouchi M, Itoh K, Nomura S, Kudo M, Mizuno N (1985) Morphology and laminar organization of electrophysiologically identified neurons in the primary auditory cortex in the cat. J Comp Neurol 235:430-447. CrossRef Medline

Morishima M, Kawaguchi Y (2006) Recurrent connection patterns of corticostriatal pyramidal cells in frontal cortex. J Neurosci 26:4394-4405. CrossRef Medline

Morishima M, Morita K, Kubota Y, Kawaguchi Y (2011) Highly differentiated projection-specific cortical subnetworks. J Neurosci 31:1038010391. CrossRef Medline

Oviedo HV, Bureau I, Svoboda K, Zador AM (2010) The functional asymmetry of auditory cortex is reflected in the organization of local cortical circuits. Nat Neurosci 13:1413-1420. CrossRef Medline

Packer AM, Yuste R (2011) Dense, unspecific connectivity of neocortical parvalbumin-positive interneurons: a canonical microcircuit for inhibition? J Neurosci 31:13260-13271. CrossRef Medline

Payne BR, Siwek DF, Lomber SG (1991) Complex transcallosal interactions in visual cortex. Vis Neurosci 6:283-289. CrossRef Medline
Peters A, Payne BR, Josephson K (1990) Transcallosal non-pyramidal cell projections from visual cortex in the cat. J Comp Neurol 302:124-142. CrossRef Medline

Petreanu L, Huber D, Sobczyk A, Svoboda K (2007) Channelrhodopsin-2assisted circuit mapping of long-range callosal projections. Nat Neurosci 10:663-668. CrossRef Medline

Petreanu L, Mao T, Sternson SM, Svoboda K (2009) The subcellular organization of neocortical excitatory connections. Nature 457:1142-1145. CrossRef Medline

Poirier P, Miljours S, Lassonde M, Lepore F (1993) Sound localization in acallosal human listeners. Brain 116:53-69. CrossRef Medline

Poirier P, Lepore F, Provençal C, Ptito M, Guillemot JP (1995) Binaural noise stimulation of auditory callosal fibers of the cat: responses to interaural time delays. Exp Brain Res 104:30-40. Medline

Pouille F, Scanziani M (2001) Enforcement of temporal fidelity in pyramidal cells by somatic feed-forward inhibition. Science 293:1159-1163. CrossRef Medline

Ravizza RJ, Straw RB, Long PD (1976) Laminar origin of efferent projections from auditory cortex in the golden Syrian hamster. Brain Res 114: 497-500. CrossRef Medline

Robinson RB, Siegelbaum SA (2003) Hyperpolarization-activated cation currents: from molecules to physiological function. Annu Rev Physiol 65:453-480. CrossRef Medline

Rouiller EM, Simm GM, Villa AE, de Ribaupierre Y, de Ribaupierre F (1991) Auditory corticocortical interconnections in the cat: evidence for parallel and hierarchical arrangement of the auditory cortical areas. Exp Brain Res 86:483-505. CrossRef Medline

Sakata S, Harris KD (2009) Laminar structure of spontaneous and sensoryevoked population activity in auditory cortex. Neuron 64:404-418. CrossRef Medline

Saldaña E, Feliciano M, Mugnaini E (1996) Distribution of descending projections from primary auditory neocortex to inferior colliculus mimics the topography of intracollicular projections. J Comp Neurol 371:15-40. CrossRef Medline

Sheets PL, Suter BA, Kiritani T, Chan CS, Surmeier DJ, Shepherd GM (2011) Corticospinal-specific HCN expression in mouse motor cortex: I(h)dependent synaptic integration as a candidate microcircuit mechanism involved in motor control. J Neurophysiol 106:2216-2231. CrossRef Medline

Stafstrom CE, Schwindt PC, Crill WE (1982) Negative slope conductance due to a persistent subthreshold sodium current in cat neocortical neurons in vitro. Brain Res 236:221-226. CrossRef Medline

Stebbings KA, Lesicko AM, Llano DA (2014) The auditory corticocollicular system: molecular and circuit-level considerations. Hear Res 314:51-59. CrossRef Medline

Stecker GC, Middlebrooks JC (2003) Distributed coding of sound locations in the auditory cortex. Biol Cybern 89:341-349. CrossRef Medline

Sun X, Chen QC, Jen PH (1996) Corticofugal control of central auditory sensitivity in the big brown bat, Eptesicus fuscus. Neurosci Lett 212:131134. CrossRef Medline

Sun YJ, Kim YJ, Ibrahim LA, Tao HW, Zhang LI (2013) Synaptic mechanisms underlying functional dichotomy between intrinsic-bursting and regular-spiking neurons in auditory cortical layer 5. J Neurosci 33:53265339. CrossRef Medline

Suter BA, O'Connor T, Iyer V, Petreanu LT, Hooks BM, Kiritani T, Svoboda K, Shepherd GM (2010) Ephus: multipurpose data acquisition software for neuroscience experiments. Front Neural Circuits 4:100. Medline

Taniguchi H, He M, Wu P, Kim S, Paik R, Sugino K, Kvitsani D, Fu Y, Lu J, Lin Y, Miyoshi G, Shima Y, Fishell G, Nelson SB, Huang ZJ (2011) A resource of Cre driver lines for genetic targeting of GABAergic neurons in cerebral cortex. Neuron 71:995-1013. CrossRef Medline

Varga C, Lee SY, Soltesz I (2010) Target-selective GABAergic control of entorhinal cortex output. Nat Neurosci 13:822-824. CrossRef Medline

Xiong Q, Oviedo HV, Trotman LC, Zador AM (2012) PTEN regulation of local and long-range connections in mouse auditory cortex. J Neurosci 32:1643-1652. CrossRef Medline

Yan J, Suga N (1996) Corticofugal modulation of time-domain processing of biosonar information in bats. Science 273:1100-1103. CrossRef Medline

Znamenskiy P, Zador AM (2013) Corticostriatal neurons in auditory cortex drive decisions during auditory discrimination. Nature 497:482-485. CrossRef Medline 